\title{
Co-production of ethanol and squalene using a Saccharomyces cerevisiae ERG1 (squalene epoxidase) mutant and agro-industrial feedstock
}

\author{
Claire M Hull' ${ }^{1}$ E Joel Loveridge ${ }^{2}$, Nicola J Rolley ${ }^{1}$, lain S Donnison ${ }^{3}$, Steven L Kelly ${ }^{1}$ and Diane E Kelly ${ }^{1 *}$
}

\begin{abstract}
Background: Genetically customised Saccharomyces cerevisiae that can produce ethanol and additional bio-based chemicals from sustainable agro-industrial feedstocks (for example, residual plant biomass) are of major interest to the biofuel industry. We investigated the microbial biorefinery concept of ethanol and squalene co-production using S. cerevisiae (strain YUG37-ERG1) wherein ERG1 (squalene epoxidase) transcription is under the control of a doxycycline-repressible tetO ${ }_{7}$-CYC1 promoter. The production of ethanol and squalene by YUG37-ERG1 grown using agriculturally sourced grass juice supplemented with doxycycline was assessed.
\end{abstract}

Results: Use of the tet ${ }_{T}-\mathrm{CYC1}$ promoter permitted regulation of ERG1 expression and squalene accumulation in YUG37-ERG1, allowing us to circumvent the lethal growth phenotype seen when ERG1 is disrupted completely. In experiments using grass juice feedstock supplemented with 0 to $50 \mu \mathrm{g}$ doxycycline $\mathrm{mL}^{-1}$, YUG37-ERG1 fermented ethanol $\left(22.5[ \pm 0.5] \mathrm{mg} \mathrm{mL}^{-1}\right)$ and accumulated the highest squalene content $\left(7.89 \pm 0.25 \mathrm{mg} \mathrm{g}^{-1}\right.$ dry biomass) and yield $\left(18.0 \pm 4.18 \mathrm{mg}\right.$ squalene $\mathrm{L}^{-1}$ ) with supplements of 5.0 and $0.025 \mu \mathrm{g}$ doxycycline $\mathrm{mL}^{-1}$, respectively. Grass juice was found to be rich in water-soluble carbohydrates $\left(61.1[ \pm 3.6] \mathrm{mg}\right.$ sugars $\left.\mathrm{mL}^{-1}\right)$ and provided excellent feedstock for growth and fermentation studies using YUG37-ERG1.

Conclusion: Residual plant biomass components from crop production and rotation systems represent possible substrates for microbial fermentation of biofuels and bio-based compounds. This study is the first to utilise S. cerevisiae for the co-production of ethanol and squalene from grass juice. Our findings underscore the value of the biorefinery approach and demonstrate the potential to integrate microbial bioprocess engineering with existing agriculture.

Keywords: Bio-based products, ERG1, Ethanol, Sterol, Squalene, Squalene epoxidase

\section{Background}

Microbial biotechnology is employed for the generation of novel industrial, pharmaceutical and medical compounds and assists in the development of more efficient commercial production processes. Microorganisms that possess the enzymatic machinery needed to unlock fuel energy from cellulosic and lignocellulosic fractions of plant biomass [1-5] and recombinant strains that can utilise alternative substrates (such as inulin [6]) for the production of additional bio-based products [7-10], are of major interest to biofuel and biorefinery industries. In

\footnotetext{
* Correspondence: D.Kelly@swansea.ac.uk

'Institute of Life Science, College of Medicine, Swansea University, Swansea, Wales SA2 8PP, UK

Full list of author information is available at the end of the article
}

the following study we investigated the potential to co-produce ethanol and squalene using a genetically customised strain of $S$. cerevisiae.

Squalene is a polyunsaturated, triterpenic hydrocarbon $(2,6,10,15,19,23$-hexamethyltetracosa-2,6,10,14,18,22hexaene) with nutritional, cosmetic, pharmaceutical and medical applications [11-14]. As a key intermediate of bacterial hopanoid and eukaryotic sterol biosynthesis $[15,16]$, squalene is ubiquitous in nature. Squalene can be derived from plant oils $[17,18]$ and the liver oil of deep sea sharks $[19,20]$. However, given the increasing commercial demand for squalene alongside growing international concern for the fate of food crops and the exploitation of marine habitats, sustainable sources of squalene are required. 
Research into the molecular controls and growth conditions that affect sterol biosynthesis [21-24] has highlighted the scope to utilise the brewing yeast $S$. cerevisiae for squalene production $[25-27,16]$. Under low oxygen or anaerobic conditions $[28,29]$ and in heme-deficient yeast [30], squalene accumulates ( $\geq 70 \%$ of total squalene fraction) in intracellular lipid droplets [16,31]. However, under aerobic growth conditions squalene is converted to ergosterol through the action of proteins encoded by the ERG (ergosterol biosynthetic) genes [23]. Of these, squalene epoxidase, encoded by $E R G 1[32,33]$ is an oxygen-requiring enzyme [34] that is essential for the initial conversion of squalene to squalene epoxide (Figure 1).

We investigated the potential to produce squalene as a bio-based chemical product of yeast fermentation using a customised S. cerevisiae strain (YUG37-ERG1) wherein ERG1 gene transcription is under the control of a doxycycline-repressible promoter that replaces the ERG1 promoter at the chromosomal locus [35,36]. Because low growth temperature and decreased oxygen availability are favourable for both ethanol fermentation and the inhibition of yeast squalene epoxidase [29,34], we envisaged the opportunity to co-produce ethanol and squalene using a biorefinery approach. For this purpose we utilised juice extracted from perennial ryegrass (Lolium perenne) [37,38]. Grass juice represents one of several fractions from L. perenne biomass that are currently under investigation as feedstock for biofuel production and microbial bioprocess engineering in the United Kingdom [39-41]).

\section{Methods}

Yeast strains and growth media

Squalene production studies were undertaken using a laboratory strain of Saccharomyces cerevisiae (YUG37-ERG1)

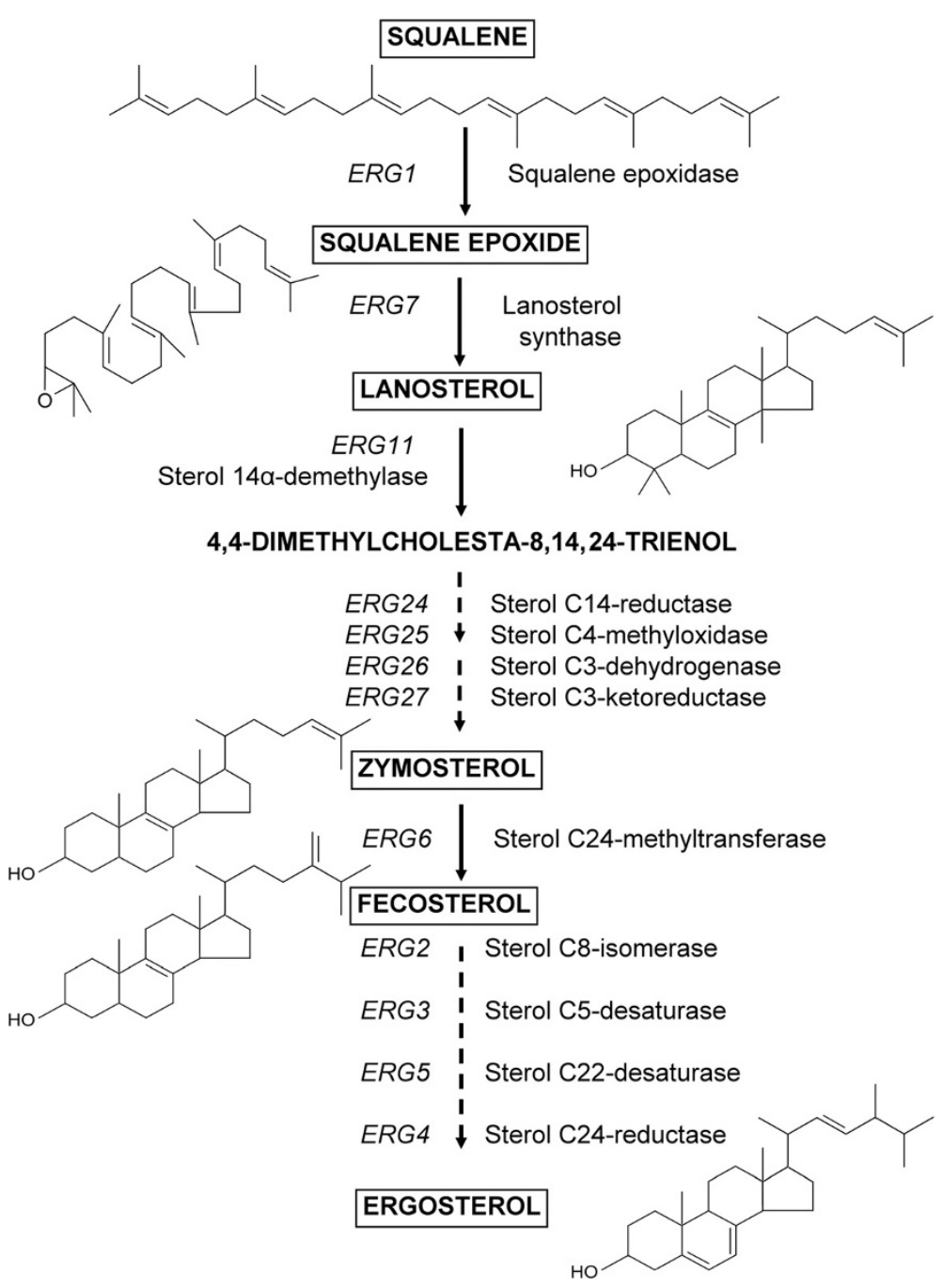

Figure 1 Ergosterol biosynthetic pathway in yeast. Structures of squalene and selected sterol intermediates (boxed); unbroken arrow = single enzymatic step; broken arrow = multiple enzymatic steps. Gene names are upper case, italicised; protein names are lower case, regular. 
in which squalene epoxidase (ERG1 protein) expression is controlled using a previously optimised doxycyclinerepressible tet $_{7}-\mathrm{CYC1}$ promoter system [35,36,42]. The wild-type $S$. cerevisiae parent strain (YUG37; Hegemann, J., unpublished) was used as a comparator during initial experiments. Both strains were routinely maintained on yeast-peptone-dextrose (YPD) medium containing (w/v): $2 \%$ glucose, 2\% Bacto Peptone and 1\% yeast extract including $2 \%$ agar when required (all media components supplied by Difco).

For ethanol and squalene co-production experiments, grass juice (GJ) feedstock was extracted from ryegrass Lolium perenne supplied by the Institute of Biological, Environmental Research and Rural Sciences (IBERS, UK) as described previously [37]. GJ was screened to remove large particulates, autoclaved $\left(121^{\circ} \mathrm{C}, 30 \mathrm{~min}\right)$ and frozen $\left(-80^{\circ} \mathrm{C}\right)$ prior to use as a growth and fermentation substrate. All other chemicals used in this study were supplied by Sigma unless otherwise stated.

\section{Gas chromatography-mass spectrometry (GC-MS) sterol analysis}

Cell pellets from experimental cultures were resuspended in 7:3 methanol:water containing $18 \%(\mathrm{w} / \mathrm{v})$ potassium hydroxide, $0.1 \%(\mathrm{w} / \mathrm{v})$ pyrogallol and $10 \mu \mathrm{g}$ cholesterol (as the internal standard), and heated at $90^{\circ} \mathrm{C}$ for $2 \mathrm{~h}$. Non-saponifiable lipids (squalene and sterols) were extracted into glass HPLC vials using $3 \times 2 \mathrm{~mL}$ hexane. Extracts were evaporated to dryness using a centrifugal evaporator (Heto Maxi dry plus) and derivatised using $100 \mu \mathrm{L}$ N,O-bis(trimethylsilyl)trifluoroacetamide and trimethylchlorosilane (BSTFA-TMCS [99:1]) and $50 \mu \mathrm{L}$ anhydrous pyridine at $70^{\circ} \mathrm{C}$ for $2 \mathrm{~h}$ [43]. Trimethylsilyl (TMS)-derivatised sterols were analysed using a 7890A GC-MS system (Agilent Technologies) with a DB$5 \mathrm{MS}$ fused silica column $(30 \mathrm{~m} \times 0.25 \mathrm{~mm} \times 0.25 \mu \mathrm{m}$ film thickness; J \& W Scientific). The oven temperature was initially held at $70^{\circ} \mathrm{C}$ for $4 \mathrm{~min}$, then increased at $25^{\circ} \mathrm{C} \mathrm{min}{ }^{-1}$ to a final temperature of $280^{\circ} \mathrm{C}$, which was held for a further $25 \mathrm{~min}$. Samples were analysed in splitless mode ( $1 \mu \mathrm{L}$ injection volume) using helium carrier gas, electron impact ionization (ion source temperature of $150^{\circ} \mathrm{C}$ ) and scanning from $\mathrm{m} / \mathrm{z} 40$ to 850 [44].

GC-MS data files were analysed using MSD Enhanced ChemStation software (Agilent Technologies Inc.) to determine squalene and sterol profiles for all isolates and for derivation of integrated peak areas. Sterols were identified by reference to retention times and mass fragmentation patterns for known standards.

\section{Sterol analysis of strains}

Initial experiments were undertaken to determine the effect of doxycycline on the growth and sterol composition of the wild-type YUG37 parent and doxycycline-repressible
YUG37-ERG1 strain. Single colonies from each were used to inoculate $10-\mathrm{mL}$ volumes of YPD medium (containing 0 to $50 \mu \mathrm{g}$ doxycycline $\mathrm{mL}^{-1}$ ) with starting cell densities of $5 \times 10^{5} \mathrm{~mL}^{-1}$. Cultures were grown in $50-\mathrm{mL}$ flasks at $30^{\circ} \mathrm{C}, 180 \mathrm{rpm}$ for $48 \mathrm{~h}$, after which time the cell biomass was harvested by centrifugation. Cell pellets were dried to constant mass for biomass ( $g$ dry weight $\mathrm{L}^{-1}$ ) determinations, and the cellular squalene and sterol content determined by GC-MS as described above.

\section{Production of ethanol and squalene from GJ feedstock Simultaneous co-production}

Experiments to achieve simultaneous co-production of ethanol and squalene were performed in 100-well honeycomb microplates using a Bioscreen C (Oy Growth Curves Ab Ltd, Finland). Uniform starting ( $\left.t_{0} \mathrm{~h}\right)$ culture densities were achieved by resuspending a single YUG37-ERG1 colony in GJ and diluting to obtain $5 \times 10^{5}$ cells $\mathrm{mL}^{-1}$ in $1 \mathrm{~mL}$ of GJ containing 0 to $50 \mu \mathrm{g}$ doxycycline $\mathrm{mL}^{-1}$. Starting cultures were vortexed and aliquoted into Bioscreen wells $(3 \times 300 \mu \mathrm{L}$ replicates per doxycycline treatment). All experiments were incubated at $20^{\circ} \mathrm{C}$ (typical of ale production) in the Bioscreen (no shaking regime) for $96 \mathrm{~h}$, with optical density readings (at $600 \mathrm{~nm}$ ) taken every $45 \mathrm{~min}$ [31]. Data was exported from the Bioscreen in ASCII format prior to analysis using Excel (Microsoft Office 2003). Dry weight determinations and GC-MS sterol analyses were performed on the biomass fractions from pooled Bioscreen wells.

Growth parameters were derived as described previously [38]. Briefly, $\triangle \mathrm{OD}$ values describe maximum OD minus minimum OD; the lag phase is defined as the length of time a culture spends at $<10 \%$ of maximum $\mathrm{OD} ; \mathrm{T}_{1 / 2} \mathrm{Max}$ values are equivalent to the time taken to reach half the maximum increase in growth of a culture $(\triangle \mathrm{OD} \times 0.5)$. Minimum (that is, fastest) doubling times $\left(\mathrm{DT}_{\text {min }}\right)$ were estimated by dividing the natural logarithm of 2 by the fastest culture growth rates $(\mu)$, where $\mu$ is the gradient of the linear trend line fitted to logtransformed OD data.

\section{Sequential production}

The stepwise production of ethanol and squalene was monitored using the Bioscreen. YUG37-ERG1 was first grown for $48 \mathrm{~h}$ at $20^{\circ} \mathrm{C}$ using GJ feedstock; at $\mathrm{t}_{48} \mathrm{~h}$ Bioscreen measurements were suspended and $100 \mu \mathrm{L}$ of supernatant removed from experimental wells for ethanol analysis [38]. This volume was immediately replaced with $100 \mu \mathrm{L}$ of fresh GJ containing doxycycline (to give a final concentration of 5 or $50 \mu \mathrm{g}$ doxycycline $\mathrm{mL}^{-1}$ ) and the Bioscreen restarted using a medium shaking regime to promote new growth and squalene accumulation. Dry weight determinations and GC-MS sterol 
analyses were performed on the biomass fractions from pooled Bioscreen wells at $t_{96} h$.

\section{Sugar and ethanol assays}

At specific time intervals $\left(t_{0} h, t_{48} h, t_{72} h\right.$ and $\left.t_{96} h\right)$ Bioscreen measurements were suspended and a $10-\mu \mathrm{L}$ volume of culture supernatant removed from representative experimental wells for ethanol and sugar analyses.

Sugar analyses were performed on suitably diluted (typically 2,500-fold) culture medium in $100 \mathrm{mM}$ potassium phosphate, $\mathrm{pH} 7.0$, containing $10 \mathrm{mM} \mathrm{MgSO}_{4}, 1 \mathrm{mM}$ $\mathrm{NAD}^{+}, 1.5 \mathrm{mM}$ ATP and $20 \mathrm{U} \mathrm{mL}^{-1}$ Leuconostoc mesenteroides glucose-6-phosphate dehydrogenase (Worthington Biochemical Corporation). Concentrations of glucose, fructose, sucrose and fructan were determined from the changes in absorbance at $340 \mathrm{~nm}$ following sequential addition of $20 \mathrm{U} \mathrm{mL}^{-1} \mathrm{~S}$. cerevisiae hexokinase (Worthington Biochemical Corporation), $20 \mathrm{U} \mathrm{mL}^{-1}$ E. coli phosphoglucose isomerase (Megazyme International Ireland Ltd), $1.5 \mathrm{U} \mathrm{mL}^{-1} \mathrm{~S}$. cerevisiae sucrase/maltase (Megazyme International Ireland Ltd) and $10 \mathrm{U} \mathrm{mL}^{-1}$ fructanase from Aspergillus niger (Megazyme International Ireland Ltd), respectively. Standards of glucose, fructose, sucrose and chicory inulin were used to calibrate the assay.

Ethanol determinations were made using a spectrophotometric ethanol assay kit (K-ETOH 11/06; Megazyme Ltd) according to manufacturer's instructions. All samples were diluted 1,000-fold with distilled water prior to analysis.

\section{Results and discussion}

Of the many microorganisms that could be employed for ethanol production, $S$. cerevisiae remains the species of choice in industrial-scale fermentation processes [45].
Similarly, whilst squalene could be sourced from alternative microbes $([16,27]$ for reviews), because of the need for specific culture conditions and because many have not been granted GRAS (generally regarded as safe) status, they cannot be exploited in a commercial setting. The present study is the first to utilise $S$. cerevisiae for the co-production of ethanol and squalene from a single feedstock. We identify clear avenues for the integration of yeast biotechnology and existing agriculture for the production of bio-based compounds, thereby adding value to such fermentations.

\section{Regulation of growth and squalene accumulation}

Data from initial experiments using YPD medium (Table 1) demonstrate the potential to maximise squalene production from $S$. cerevisiae through regulation of ERG1 expression (Figure 1) and indicate that in order to achieve an optimal squalene yield, repression of ERG1 gene expression must be sufficient to result in increased squalene accumulation, but not complete growth inhibition. The highest squalene content $\left(7.85 \pm 0.02 \mathrm{mg} \mathrm{g}^{-1}\right.$ dry biomass) was recorded in YUG37-ERG1 grown using YPD supplemented with $50 \mu \mathrm{g}$ doxycycline $\mathrm{mL}^{-1}$; however, because the biomass of these cultures was low $\left(1.39 \pm 0.12 \mathrm{mg} \mathrm{L}^{-1}\right)$, the squalene titre was sub-optimal $\left(10.87 \pm 0.93 \mathrm{mg} \mathrm{L}^{-1}\right)$. Conversely, whilst the squalene content of YUG37-ERG1 grown with $0.025 \mu \mathrm{g}$ doxycycline $\mathrm{mL}^{-1}$ was comparatively lower $\left(3.57 \pm 0.2 \mathrm{mg} \mathrm{g}^{-1}\right.$ dry biomass), higher overall culture growth $\left(4.3 \pm 0.28 \mathrm{mg} \mathrm{L}^{-1}\right)$ supported an improved squalene titre (Table $1 ; 15.04 \pm 1.42 \mathrm{mg} \mathrm{L}^{-1}$ ).

\section{Alterations in yeast sterol composition}

Doxycycline did not alter the sterol composition of the YUG37 parent across the range of doxycycline

Table 1 Phenotypic sterol analysis of YUG37 parent and YUG37-ERG1 mutant

\begin{tabular}{|c|c|c|c|c|c|c|c|c|}
\hline \multirow{2}{*}{$\begin{array}{l}\text { DOX } \\
\left(\mu \mathrm{g} \mathrm{mL}^{-1}\right)\end{array}$} & \multirow[b]{2}{*}{ Strain } & \multicolumn{4}{|c|}{ Sterol composition (mg sterol $\mathrm{g}^{-1}$ ) } & \multirow{2}{*}{$\begin{array}{l}\text { Total } \\
\left(\mathrm{mg} \mathrm{g}^{-1}\right)\end{array}$} & \multirow{2}{*}{$\begin{array}{l}\text { Biomass } \\
\left(\mathrm{g} \mathrm{L}^{-1}\right)\end{array}$} & \multirow{2}{*}{$\begin{array}{l}\text { Squalene titre } \\
\left(\mathrm{mg} \mathrm{L}^{-1}\right)\end{array}$} \\
\hline & & ${ }^{\mathrm{a}} 14 a-D M$ & ${ }^{b} 14 a-M$ & Ergosterol & Squalene & & & \\
\hline \multirow[t]{2}{*}{0} & YUG37 & $1.45[0.27]$ & $0.33[0.03]$ & $3.27[0.39]$ & $0.16[0.08]$ & $5.31[0.19]$ & $3.75[0.35]$ & $0.50[0.11]$ \\
\hline & YUG37-ERG1 & $1.51[0.29]$ & $0.39[0.07]$ & $3.08[029]$ & $0.40[0.03]$ & $5.28[0.24]$ & $4.55[0.21]$ & $1.76[0.02]$ \\
\hline \multirow[t]{2}{*}{0.025} & YUG37 & $1.30[0.16]$ & $0.20[0.06]$ & $3.09[0.35]$ & $0.17[0.13]$ & $4.75[0.02]$ & $4.25[0.21]$ & $0.55[0.31]$ \\
\hline & YUG37-ERG1 & $1.55[0.09]$ & $0.40[0.03]$ & $2.43[0.08]$ & $3.57[0.20]$ & $7.88[0.31]$ & $4.30[0.28]$ & $15.04[1.42]$ \\
\hline \multirow[t]{2}{*}{0.05} & YUG37 & $1.47[0.22]$ & $0.26[0.03]$ & $3.03[0.14]$ & $0.30[0.04]$ & $4.98[0.19]$ & $3.90[0.14]$ & $1.23[0.03]$ \\
\hline & YUG37-ERG1 & $0.78[0.10]$ & $0.40[0.08]$ & $2.20[0.09]$ & $4.24[0.30]$ & $7.55[0.33]$ & $2.50[0.28]$ & $10.31[0.79]$ \\
\hline \multirow[t]{2}{*}{0.5} & YUG37 & $1.36[0.22]$ & $0.24[0.06]$ & $2.79[0.32]$ & $0.23[0.06]$ & $4.77[0.30]$ & $3.95[0.07]$ & $1.02[0.14]$ \\
\hline & YUG37-ERG1 & $0.45[0.01]$ & $0.17[0.02]$ & 1.58 [0.12] & $6.75[0.20]$ & $8.96[0.06]$ & $1.75[0.21]$ & $11.93[1.27]$ \\
\hline \multirow[t]{2}{*}{5} & YUG37 & 1.54 [0.29] & $0.29[0.06]$ & $3.06[0.42]$ & $0.20[0.10]$ & $5.03[0.11]$ & $3.60[0.42]$ & $0.57[0.12]$ \\
\hline & YUG37-ERG1 & $0.21[0.04]$ & $0.08[0.04]$ & $1.49[0.02]$ & $7.66[0.01]$ & $9.45[0.08]$ & $1.48[0.11]$ & $11.30[0.82]$ \\
\hline \multirow[t]{2}{*}{50} & YUG37 & $1.21[0.23]$ & $0.23[0.01]$ & $2.93[0.26]$ & $0.14[0.06]$ & $4.63[0.27]$ & $3.75[0.35]$ & $0.59[0.05]$ \\
\hline & YUG37-ERG1 & $0.11[0.03]$ & $0.02[0.01]$ & $1.50[0.03]$ & $7.85[0.02]$ & $9.48[0.10]$ & $1.39[0.12]$ & $10.87[0.93]$ \\
\hline
\end{tabular}

All cultures grown at $30^{\circ} \mathrm{C}, 180 \mathrm{rpm}$ for $48 \mathrm{~h}$ on YPD medium. Mean values ( $\mathrm{n}=3$ [ $\pm \mathrm{SD}$ ]); DOX = doxycycline. Maximum squalene content and yield are emboldened. ${ }^{\mathrm{a}}=$ sum of all $14 \mathrm{a}$-demethylated sterols; ${ }^{\mathrm{b}}=$ sum of $14 \mathrm{a}$-methylated sterols. 
concentrations ( 0 to $50 \mu \mathrm{g} \mathrm{mL} \mathrm{m}^{-1}$ ) tested (Table 1$)$. That no significant differences in the proportion of $14 \alpha-$ demethylated or $14 \alpha$-methylated sterol intermediates were detected in treated YUG37 cultures (Figure 2C and 2D) indicates that doxycycline did not affect the function of other ERG genes or proteins involved in ergosterol biosynthesis (Figure 1). Changes in the sterol composition of doxycycline-treated YUG37-ERG1 cultures, namely overall decreases in both $14 \alpha$-demethylated and $14 \alpha$-methylated sterol intermediates, are consistent with the specific inhibition of squalene epoxidase expression. Enhanced accumulation of squalene at the expense of other sterol intermediates has previously been reported in $S$. cerevisiae treated with the squalene epoxidase inhibitor, terbinafine [27].

\section{Growth and ethanol fermentation: grass juice feedstock} Growth parameters for YUG37-ERG1 grown using grass juice (GJ) (Table 2 and Figure 3) underscore data from previous studies that highlight its potential as a feedstock for S. cerevisiae [37,38]. GJ was rich in watersoluble carbohydrates (Table 3 ) that were readily utilised for growth and ethanol fermentation. In simultaneous ethanol and squalene production experiments, maximum concentrations of ethanol (20 to $23 \mathrm{mg} \mathrm{mL}^{-1}$ ) were produced after $72 \mathrm{~h}$ of fermentation. Similar concentrations $\left(22.5[ \pm 0.5] \mathrm{mg}\right.$ ethanol $\left.\mathrm{mL}^{-1}\right)$ were recorded in sequential production experiments (Table 4, asterisked data) after just $48 \mathrm{~h}$, prior to the addition of doxycycline. Taken as a whole, the ethanol titres in this study are comparable to those achieved previously using GJ and alternative wild-type laboratory strains of S. cerevisiae $[37,38]$.

\section{Ethanol titres}

High ethanol titres have recently been achieved using pure inulin and soybean feedstock and an engineered yeast strain (Saccharomyces sp. W0) expressing the inulinase gene from Pichia guilliermondii [10]. Work is now needed to address the potential to use recombinant yeast to ferment grass juice to ethanol on an industrial scale and alternative (for example, flocculating [46-48] or high ethanol producing [10] host strains of $S$. cerevisiae.

\section{Squalene accumulation: grass juice feedstock}

The highest squalene content $\left(7.89 \pm 0.25 \mathrm{mg} \mathrm{g}^{-1}\right.$ dry biomass) and squalene titres $\left(18.0 \pm 4.18 \mathrm{mg} \mathrm{L}^{-1}\right)$ were achieved during simultaneous production experiments in which GJ was supplemented (at $t_{0} h$ ) with 5 and $0.025 \mu \mathrm{g}$ doxycycline $\mathrm{mL}^{-1}$, respectively (Table 4 and Figure 4). In subsequent experiments the highest total biomass ( 5.2 to $5.4 \mathrm{~g} \mathrm{~L}^{-1}$ ) was recorded $48 \mathrm{~h}$ after the removal of culture supernatant and the addition of fresh

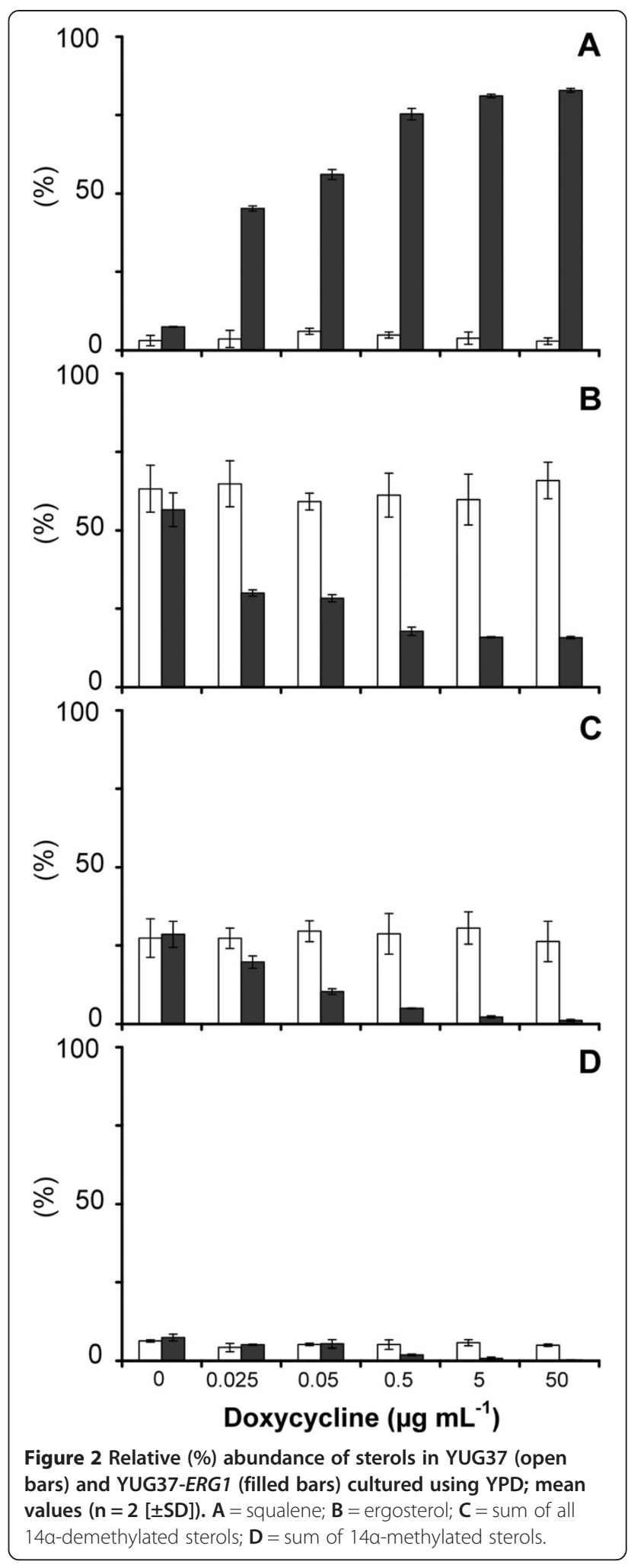

doxycycline-supplemented GJ (Table 4, asterisked data). However, concomitant with the accumulation of ergosterol during initial growth in the absence of doxycycline 
Table 2 Growth parameters for YUG37-ERG1 cultured on $\mathrm{GJ}$ at $20^{\circ} \mathrm{C}$ in the Bioscreen

\begin{tabular}{|c|c|c|c|c|}
\hline $\begin{array}{l}\text { DOX } \\
\left(\mu \mathrm{g} \mathrm{mL}^{-1}\right)\end{array}$ & $\Delta O D$ & Lag phase (h) & $\mathrm{T}_{1 / 2} \operatorname{Max}(\mathrm{h})$ & $D T_{\min }(\mathrm{h})$ \\
\hline 0 & $1.69[0.01]$ & $11.3[0.4]$ & $21.8[0.4]$ & $3.8[0.4]$ \\
\hline 0.025 & $1.66[0.01]$ & $11.4[0.2]$ & $22.6[0.5]$ & $4.3[0.1]$ \\
\hline 0.05 & $1.63[0.01]$ & $11.5[0.4]$ & $24.1[1.2]$ & $5.4[0.2]$ \\
\hline 0.1 & $1.54[0.01]$ & $11.5[0.7]$ & $28.9[0.9]$ & $6.0[0.7]$ \\
\hline 0.5 & $1.43[0.02]$ & $11.8[0.4]$ & $31.5[0.7]$ & $8.6[0.5]$ \\
\hline 1 & $1.34[0.02]$ & $11.5[0.4]$ & $35.8[0.4]$ & $10.3[0.4]$ \\
\hline 5 & $1.35[0.01]$ & $11.5[0.7]$ & $38.0[2.8]$ & $10.3[0.7]$ \\
\hline 50 & $1.34[0.02]$ & $10.9[0.5]$ & $37.0[1.4]$ & $10.4[0.9]$ \\
\hline
\end{tabular}

Mean values $(n=3[ \pm S D])$. DOX $=$ doxycycline; $\Delta O D=$ maximum minus minimum optical density reading at $600 \mathrm{~nm}$; Lag phase $=$ length of time culture remains at $<10 \%$ of maximum OD; $T_{1 / 2} M a x=$ time taken to achieve half maximal culture growth (maximum OD minus minimum $\mathrm{OD} \times 0.5$ ); $\mathrm{DT}_{\min }=$ fastest observed doubling time.

$\left(4.34 \pm 0.07\right.$ and $3.80 \pm 0.37 \mathrm{mg}$ ergosterol $\mathrm{g}^{-1}$ dry biomass) squalene titres $(12.0 \pm 1.83$ and $12.7 \pm 0.24 \mathrm{~g}$ squalene $\mathrm{L}^{-1}$, respectively) were lower than those recorded in simultaneous production experiments in which doxycycline was present from $t_{0} h$. The use of bioreactors to maintain optimal growth and fermentation conditions for ethanol and squalene co-production using YUG37$E R G 1$ is now an avenue for bioprocess development and commercial scale-up.

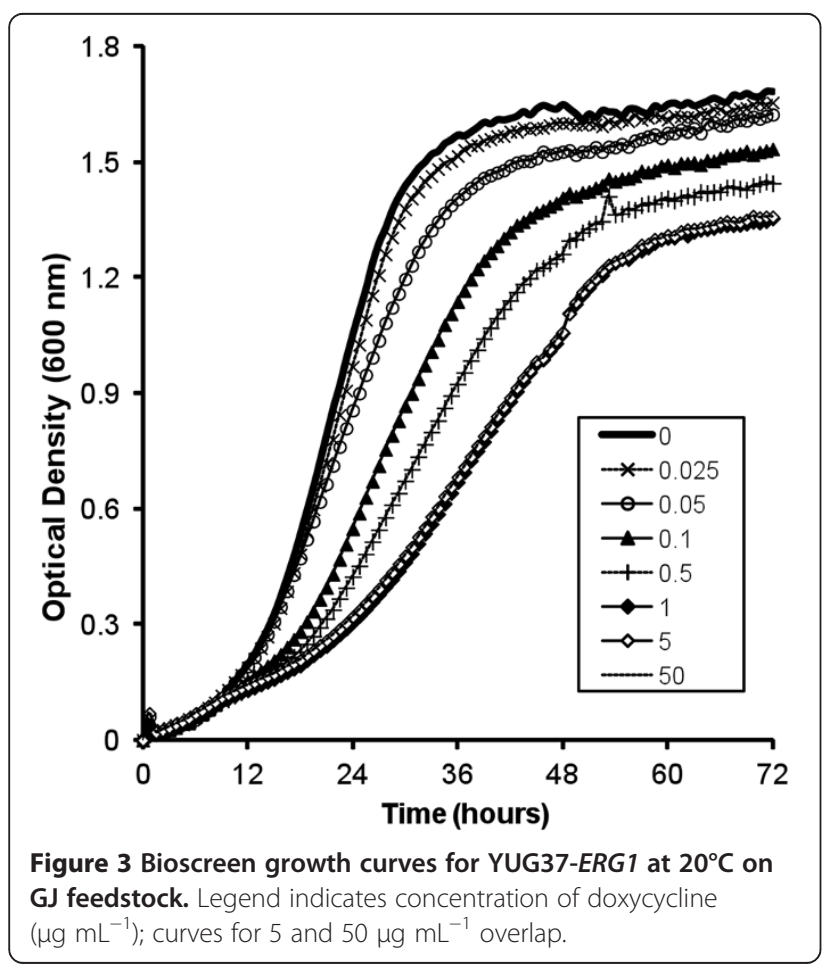

Table 3 Glucose, fructose, sucrose and fructan content of GJ media during fermentation with YUG37-ERG1

\begin{tabular}{llllll}
\hline \multirow{2}{*}{ Sugar } & \multicolumn{6}{l}{ Content in medium $\left(\mathbf{m g ~ m L}^{\mathbf{- 1}}\right)$} \\
\cline { 2 - 6 } & $\mathbf{G J} \mathbf{t}_{\mathbf{0}}$ & $\mathbf{G J ~ t}_{\mathbf{4 8}}$ & $\mathbf{G J} \mathbf{t}_{\mathbf{9 6}}$ & $\mathbf{G J}^{\mathbf{0 . 5}} \mathbf{t}_{\mathbf{9 6}}$ & $\mathbf{G J}^{\mathbf{5 0}} \mathbf{t}_{\mathbf{9 6}}$ \\
\hline Glucose & $7.3[1.8]$ & $0.2[0.2]$ & - & - & - \\
Fructose & $22.2[2.0]$ & $0.4[0.1]$ & $0.5[0.1]$ & $0.8[0.5]$ & $0.6[0.1]$ \\
Sucrose & $0.5[0.3]$ & $0.2[0.2]$ & $0.1[0.2]$ & $0.2[0.2]$ & $0.7[0.2]$ \\
Fructan & $31.2[2.4]$ & $17.8[0.5]$ & $17.4[0.04]$ & $17.8[1.2]$ & $15.7[2.9]$ \\
Total & $61.1[3.6]$ & $18.5[0.9]$ & $18.1[0.2]$ & $18.9[1.4]$ & $16.9[2.9]$ \\
\hline
\end{tabular}

Mean values $(n=2[ \pm S D])$. Superscripts 0.5 and 50 refer to media containing 0.5 and $50 \mu \mathrm{g} \mathrm{mL}^{-1}$ doxycycline, respectively; Strikethrough = not detected.

\section{Advantages of the doxycycline-regulatable promoter system}

The maximum squalene titres achieved using GJ in the present study are comparable to those recently reported for $S$. cerevisiae grown on standard yeast media in the presence of the squalene epoxidase inhibitor, terbinafine [27]. However, in that study a terbinafine concentration of $300 \mu \mathrm{M}$ was required to produce the optimum squalene titre $\left(20.70 \pm 1.00 \mathrm{mg} \mathrm{L}^{-1}\right)$. In our work, a comparable squalene titre was achieved by repressing overall ERG1 gene transcription with just $0.025 \mu \mathrm{g} \mathrm{mL} \mathrm{L}^{-1}$ $(0.05 \mu \mathrm{M})$ doxycycline (Table 4$)$. In addition to its sensitivity, use of the promoter system to attenuate squalene epoxidase synthesis at the ERG1 gene level circumvents the potential to select for protein-level mutations that conserve squalene epoxidase function (that is, normal ergosterol biosynthesis) in yeast cultures treated with protein inhibitors (for example, terbinafine [27]). Terbinafine resistant $S$. cerevisiae harbouring single amino acid substitutions in the Erg1 protein (either L251F, F402L, F420L or P430S) have already been reported [49]. The economic feasibility of using the $t^{2} \mathrm{O}_{7}-\mathrm{CYC} 1$ promoter system to harness squalene production on an industrial scale is currently being assessed. Owing to the demand and high commercial value of squalene, it is anticipated that the costs of doxycycline supplementation would likely be offset by those recovered from squalene production. The design and use of alternative yeast promoter systems (such as GAL1, CUP1 and MET3 [[50] for summary]) is possible. However, it is important that the promoter of choice does not have an effect on yeast physiology, and that is what is so attractive about the doxycycline system.

\section{Grass biomass and microbial bioprocess engineering}

Grass biomass comprises several fractions (for example, water-soluble sugars, fructans, hemicellulose, cellulose [39]) that could be used as substrates for the production of biofuels and other value-added bio-based compounds. In the present study, $55 \%$ of the original fructan was still present in grass juice at the end of the fermentation 
Table 4 Sterol composition, dry weight biomass and squalene titre of YUG37-ERG1 cultured using GJ

\begin{tabular}{|c|c|c|c|c|c|c|c|}
\hline \multirow{2}{*}{$\begin{array}{l}\text { DOX } \\
\left(\mu \mathrm{gL} \mathrm{m}^{-1}\right)\end{array}$} & \multicolumn{4}{|c|}{ Sterol composition (mg sterol $\mathrm{g}^{-1}$ ) } & \multirow{2}{*}{$\begin{array}{l}\text { Total } \\
\left(\mathrm{mg} \mathrm{g}^{-1}\right)\end{array}$} & \multirow{2}{*}{$\begin{array}{l}\text { Biomass } \\
\left(g^{-1}\right)\end{array}$} & \multirow{2}{*}{$\begin{array}{l}\text { Squalene titre } \\
\left(\mathrm{mg} \mathrm{L}^{-1}\right)\end{array}$} \\
\hline & ${ }^{a} 14 a-D M$ & ${ }^{b} 14 a-M$ & Ergosterol & Squalene & & & \\
\hline 0 & $1.09[0.23]$ & $0.47[0.16]$ & $3.51[0.83]$ & $0.19[0.09]$ & $5.25[0.35]$ & $4.80[0.28]$ & $0.88[0.39]$ \\
\hline 0.025 & $0.97[0.46]$ & $0.27[0.27]$ & $2.64[0.40]$ & $3.98[0.68]$ & $7.85[0.35]$ & $4.50[0.28]$ & $18.0[4.18]$ \\
\hline 0.05 & $0.73[0.21]$ & $0.28[0.17]$ & $2.00[0.34]$ & $5.14[0.25]$ & $8.15[0.21]$ & $2.25[0.21]$ & $11.5[0.53]$ \\
\hline 0.5 & $0.31[0.07]$ & $0.09[0.01]$ & $2.63[0.48]$ & $5.92[0.27]$ & $8.95[0.15]$ & $1.78[0.11]$ & $10.5[1.11]$ \\
\hline 5 & $0.10[0.01]$ & $0.01[0.01]$ & $1.27[0.15]$ & $7.89[0.25]$ & $9.28[0.11]$ & $1.44[0.04]$ & $11.4[0.70]$ \\
\hline 50 & - & - & $1.31[0.46]$ & $7.84[0.25]$ & $9.15[0.21]$ & $1.45[0.07]$ & $11.4[0.20]$ \\
\hline$* * 5$ & - & - & $4.34[0.07]$ & $2.22[0.28]$ & $6.55[0.35]$ & $5.40[0.14]$ & $12.0[1.83]$ \\
\hline$* * 50$ & - & - & $3.80[0.37]$ & $2.45[0.02]$ & $6.25[0.35]$ & $5.20[0.14]$ & $12.7[0.24]$ \\
\hline
\end{tabular}

All cultures maintained at $20^{\circ} \mathrm{C}$ in the Bioscreen. Mean values $(n=3[ \pm \mathrm{SD}]$ ); DOX $=$ doxycycline. Maximum squalene content and titre are emboldened. Asterisks indicate sequential production experiments supplemented with additional GJ + DOX after $48 \mathrm{~h}$ growth in the absence of DOX.

Strikethrough $=$ not detected.

${ }^{a}=$ sum of all $14 a$-demethylated sterols; ${ }^{b}=$ sum of $14 a-$-methylated sterols.

experiments (Table 3). The enzymatic hydrolysis of fructans in grass juice prior to yeast fermentation experiments has already been reported [37] and recombinant yeast that can simultaneously saccharify and ferment grass fructans to ethanol has recently been achieved [38]. Because simultaneous saccharification and fermentation requires fewer steps than enzyme addition, we envisage further modification of YUG37-ERG1 to enable utilisation of fructan; this could enhance the efficiency and yields of ethanol and squalene produced from grass juice. Use of alternative yeast species (for example, $S$. kudriavzevii [51]) and existing recombinant industrial strains (for example, see [52]) that can utilise alternative substrates and agro-industrial feedstocks for the production of squalene and ethanol is also of interest.

\section{Conclusion}

Results from this study clearly demonstrate proof of principle that squalene production can be harnessed in $S$. cerevisiae by repressing ERG1 gene transcription. The potential to co-produce ethanol and squalene (and/or additional bio-based products) from a single feedstock using yeast is realistic and warrants further investigation.

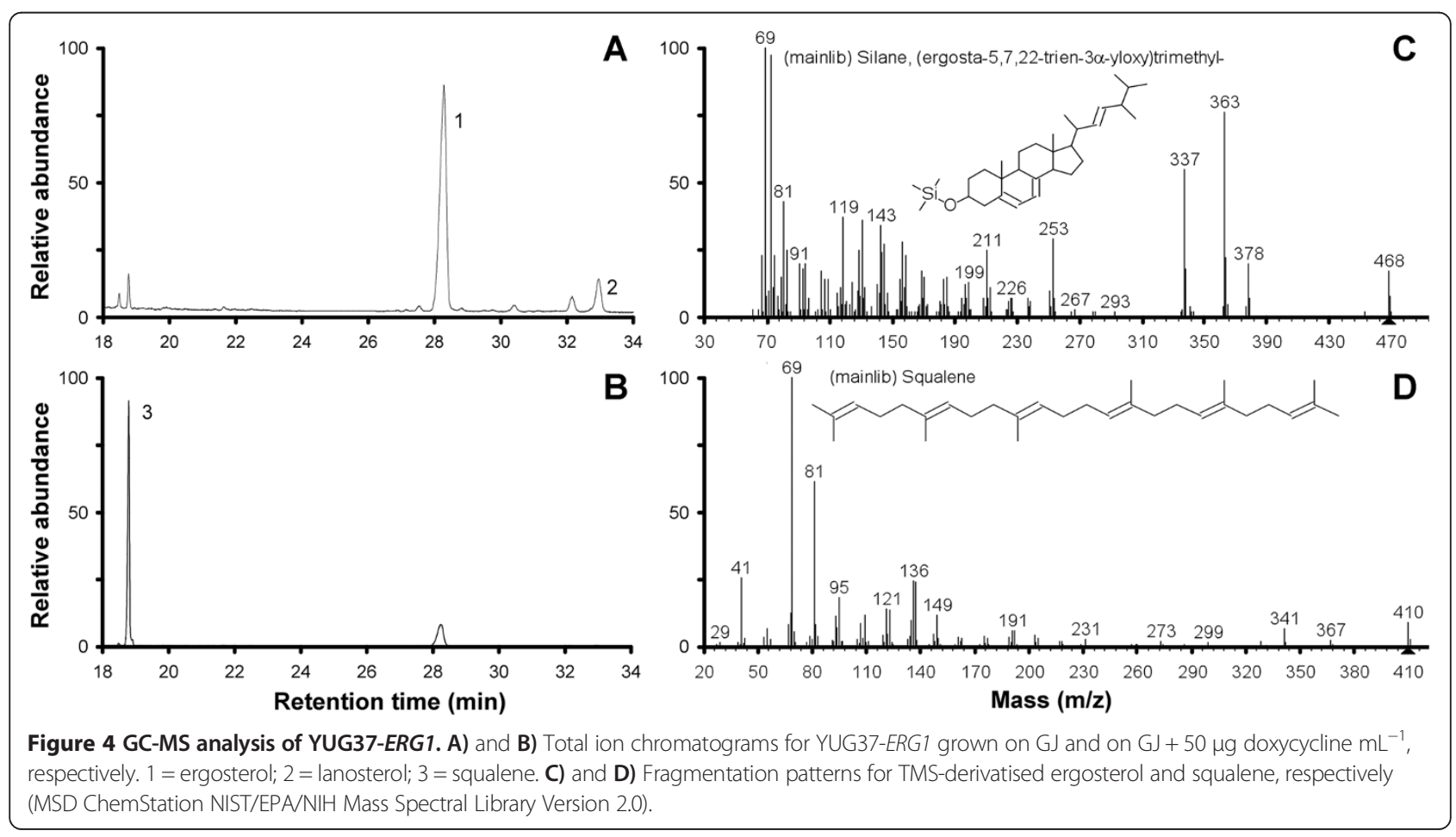




\section{Abbreviations}

ATP: adenosine triphosphate; ERG1: squalene epoxidase; GJ: grass juice; GRAS: generally regarded as safe; $\mathrm{MgSO}_{4}$ : magnesium sulphate; OD: optical density; YPD: yeast-peptone-dextrose.

\section{Competing interests}

The authors declare that they have no competing interests.

\section{Authors' contributions}

$\mathrm{CMH}$ performed the experiments, analyzed the results and prepared the initia draft of the manuscript. EJL participated in the sugar analysis. NJR constructed the YUG37-ERG1 strain and contributed to the phenotypic analysis. ISD contributed expertise in grass feedstock and to the draft of the final submission. DEK and SLK conceived and coordinated the study and revised the manuscript All authors participated in the correction of the manuscript, and approved the final version.

\section{Acknowledgements}

Funding for this study was provided by the Biotechnology and Biological Sciences Research Council (2/E13805) and the BEACON Convergence project supported by the Welsh Government from the European Regional Development Fund (ERDF) of the European Union.

\section{Author details}

${ }^{1}$ Institute of Life Science, College of Medicine, Swansea University, Swansea, Wales SA2 8PP, UK. ${ }^{2}$ School of Chemistry, Cardiff University, Cardiff, Wales CF10 3AT, UK. ${ }^{3}$ Institute of Biological, Environmental \& Rural Sciences, Aberystwyth University, Gogerddan, Aberystwyth, Wales SY23 3EE, UK.

Received: 29 January 2014 Accepted: 29 August 2014

Published online: 24 September 2014

\section{References}

1. Dashtban M, Schraft H, Qin W: Fungal bioconversion of lignocellulosic residues; opportunities \& perspectives. Int J Biol Sci 2009, 5:578-595.

2. Kumar P, Barrett DM, Delwiche MJ, Stroeve P: Methods for pretreatment of lignocellulosic biomass for efficient hydrolysis and biofuel production. Ind Eng Chem Res 2009, 48:3713-3729.

3. Margeot A, Hahn-Hägerdal B, Edlund M, Slade R, Monot F: New improvements for lignocellulosic ethanol. Curr Opin Biotechnol 2009, 20:372-380.

4. Matsushika A, Inoue H, Kodaki T, Sawayama S: Ethanol production from xylose in engineered Saccharomyces cerevisiae strains: current state and perspectives. Appl Microbiol Biotechnol 2009, 84:37-53.

5. Wiedemann B, Boles E: Codon-optimized bacterial genes improve $\mathrm{L}$-arabinose fermentation in recombinant Saccharomyces cerevisiae. Appl Environ Microbiol 2008, 74:2043-2050.

6. Chi C, Zhang Z, Ge W, Jameel H: The relationship between two methods for evaluating five-carbon sugars in eucalyptus extraction liquor. BioResources 2009, 4:537-543.

7. Abbott DA, Zelle RM, Jack T, Pronk JT, Van Maris AJA: Metabolic engineering of Saccharomyces cerevisiae for production of carboxylic acids: current status and challenges. FEMS Yeast Res 2009, 9(8):1123-1136.

8. Pirkov I, Albers E, Norbeck J, Larsson C: Ethylene production by metabolic engineering of the yeast Saccharomyces cerevisiae. Metab Eng 2008, 10:276-280

9. Thomsen $\mathrm{MH}$, Hauggaard-Nielsen $\mathrm{H}$, Petersson $\mathrm{A}$, Thomsen $\mathrm{AB}$, Jensen $\mathrm{ES}$. Sustainable bioethanol production combining biorefinery principles and intercropping strategies. Energy solutions for sustainable development. Risø International Energy Conference; 2007:22-24.

10. Zhang Y, Du H, Qian X, Chen EY-X: Ionic liquid - water mixtures: enhanced $\mathrm{Kw}$ for efficient cellulosic biomass conversion. Energy Fuels 2010, 4:2410-2417.

11. Trichopoulou A, Lagiou P, Kuper H, Trichopoulos D: Cancer and Mediterranean dietary traditions. Cancer Epidemiol Biomarkers Prev 2000, 9(9):869-873.

12. Huang Z-R, Lin Y-K, Fang J-Y: Biological and pharmacological activities of squalene and related compounds: potential uses in cosmetic dermatology. Molecules 2009, 14(1):540-554.

13. Fox CB: Squalene emulsions for parenteral vaccine and drug delivery. Molecules 2009 , 14(9):3286-3312.
14. Reddy $L H$, Couvreur P: Squalene: a natural triterpene for use in disease management and therapy. Adv Drug Deliv Rev 2009, 61(15):1412-1426.

15. Ourisson G, Rohmer M, Poralla K: Prokaryotic hopanoids and other polyterpenoid sterol surrogates. Annu Rev Microbiol 1987, 41:301-333.

16. Spanova M, Daum G: Squalene - biochemistry, molecular biology, process biotechnology, and applications. Eur J Lipid Sci Technol 2011, 113(11):1299-1320.

17. Newmark HL: Squalene, olive oil, and cancer risk: review and hypothesis. Ann N Y Acad Sci 1999, 889:193-203

18. Owen RW, Mier W, Giacosa A, Hull WE, Spiegelhalder B, Bartsch H: Phenolic compounds and squalene in olive oils: the concentration and antioxidant potential of total phenols, simple phenols, secoiridoids, lignans and squalene. Food Chem Toxicol 2000, 38(8):647-659.

19. Gershbein LL, Singh EJ: Hydrocarbons of dogfish and cod livers and herring oil. J Am Oil Chem Soc 1969, 46(10):554-557.

20. Catchpole OJ, von Kamp JC, Grey JB: Extraction of squalene from shark liver oil in a packed column using supercritical carbon dioxide. Ind Eng Chem Res 1997, 36(10):4318-4324

21. Parks LW: Metabolism of sterols in yeast. CRC Crit Rev Microbiol 1978, 6(4):301-341.

22. Daum G, Lees ND, Bard M, Dickson R: Biochemistry, cell biology and molecular biology of lipids of Saccharomyces cerevisiae. Yeast 1998, 14(16):1471-1510.

23. Daum G, Tuller G, Nemec T, Hrastnik C, Balliano G, Cattel L, Milla P, Rocco F, Conzelmann A, Vionnet C, Kelly DE, Kelly S, Schweizer E, Schuller HJ, Hojad U, Greiner E, Finger K: Systematic analysis of yeast strains with possible defects in lipid metabolism. Yeast 1999, 15(7):601-614.

24. Lees ND, Bard M, Kirsch DR: Biochemistry and molecular biology of sterol synthesis in Saccharomyces cerevisiae. Crit Rev Biochem Mol Biol 1999. 34(1):33-47.

25. Kamimura K, Hidaka M, Masaki H, Uozumi T: Construction of squaleneaccumulating Saccharomyces cerevisiae mutants by gene disruption through homologous recombination. Appl Microbiol Biotechnol 1994, 42(2-3):353-357.

26. Mantzouridou F, Tsimidou MZ: Observations on squalene accumulation in Saccharomyces cerevisiae due to the manipulation of HMG2 and ERG6. FEMS Yeast Res 2010, 10(6):699-707

27. Naziri E, Mantzouridou F, Tsimidou MZ: Enhanced squalene production by wild-type Saccharomyces cerevisiae strains using safe chemical means. J Agric Food Chem 2011, 59(18):9980-9989.

28. Daum G, Glatz H, Paltauf F: Lipid metabolism in an inositol deficient yeast, Saccharomyces carlsbergensis: influence of temperature and anaerobiosis on cellular lipid composition. Biochim Biophys Acta 1977, 488(3):484-492.

29. Mantzouridou F, Naziri E, Tsimidou MZ: Squalene versus ergosterol formation using Saccharomyces cerevisiae: combined effect of oxygen supply, inoculum size, and fermentation time on yield and selectivity of the bioprocess. J Agric Food Chem 2009, 57(14):6189-6198.

30. Gollub EG, Liu K, Dayan J, Adlersberg M, Sprinson DB: Yeast mutants deficient in heme biosynthesis and a heme mutant additionally blocked in cyclization of 2,3-oxidosqualene. J Biol Chem 1977, 252(9):2846-2854.

31. Spanova M, Zweytick D, Lohner K, Klug L, Leitner E, Hermetter A, Daum G: Influence of squalene on lipid particle/droplet and membrane organization in the yeast Saccharomyces cerevisiae. Biochim Biophys Acta 2012, 1821(4):647-653

32. Jandrositz A, Turnowsky F, Hogenauer G: The gene encoding squalene epoxidase from Saccharomyces cerevisiae - cloning and characterization. Gene 1991, 107(1):155-160.

33. Landl KM, Klosch B, Turnowsky F: ERG1, encoding squalene epoxidase, is located on the right arm of chromosome VII of Saccharomyces cerevisiae. Yeast 1996, 12(6):609-613.

34. Jahnke L, Klein HP: Oxygen requirements for formation and activity of the squalene epoxidase in Saccharomyces cerevisiae. J Bacterio 1983, 155(2):488-492

35. Garí E, Piedrafita L, Aldea M, Herrero E: A set of vectors with a tetracyclineregulatable promoter system for modulated gene expression in Saccharomyces cerevisiae. Yeast 1997, 13(9):837-848.

36. Groeneveld P, Rolley N, Kell DB, Kelly SL, Kelly DE: Metabolic contro analysis and engineering of the yeast sterol biosynthetic pathway. Mol Biol Rep 2002, 29(1-2):27-29.

37. Martel CM, Warrilow AGS, Jackson CJ, Mullins JGL, Togawa RC, Parker JE, Morris MS, Donnison IS, Kelly DE, Kelly SL: Expression, purification and use 
of the soluble domain of Lactobacillus paracasei beta-fructosidase to optimise production of bioethanol from grass fructans. Bioresour Technol 2010, 101(12):4395-4402.

38. Martel CM, Parker JE, Jackson CJ, Warrilow AGS, Rolley N, Greig C, Morris SM Donnison IS, Kelly DE, Kelly SL: Expression of bacterial levanase in yeast enables simultaneous saccharification and fermentation of grass juice to bioethanol. Bioresour Technol 2011, 102(2):1503-1508.

39. Charlton A, Elias R, Fish S, Fowler P, Gallagher J: The biorefining opportunities in Wales: understanding the scope for building a sustainable, biorenewable economy using plant biomass. Chem Eng Res Design 2009, 87(9):1147-1161

40. Farrar K, Bryant DN, Turner L, Gallagher JA, Thomas A, Farrell M, Humphreys MO, Donnison IS: Breeding for bio-ethanol production in Lolium perenne L.: association of allelic variation with high water-soluble carbohydrate content. Bioresour Technol 2012, 5:149-157.

41. Kyazze G, Dinsdale R, Hawkes FR, Guwy AJ, Premier GC, Donnison IS: Direct fermentation of fodder maize, chicory fructans and perennial ryegrass to hydrogen using mixed microflora. Bioresour Technol 2008, 99:8833-8839.

42. Martel CM, Parker JE, Warrilow AGS, Rolley NJ, Kelly SL, Kelly DE:

Complementation of a Saccharomyces cerevisiae ERG11/CYP51 (sterol 14a-demethylase) doxycycline-regulated mutant and screening of the azole sensitivity of Aspergillus fumigatus isoenzymes CYP51A and CYP51B. Antimicrob Agents Chemother 2010, 54(11):4920-4923.

43. Martel CM, Parker JE, Bader O, Weig M, Gross U, Warrilow AGS, Kelly DE, Kelly SL: A clinical isolate of Candida albicans with mutations in ERG11 (encoding sterol 14a-demethylase) and ERG5 (encoding C22-desaturase) is cross resistant to azoles and amphotericin B. Antimicrob Agents Chemother 2010, 54(9):3578-3583.

44. Martel CM, Parker JE, Bader O, Weig M, Gross U, Warrilow AGS, Rolley N, Kelly DE, Kelly SL: Identification and characterization of four azole resistant erg3 mutants of Candida albicans. Antimicrob Agents Chemother 2010, 54(11):4527-4533.

45. Bai FW, Anderson WA, Moo-Young M: Ethanol fermentation technologies from sugar and starch feedstocks. Biotechnol Adv 2008, 26(1):89-105.

46. Choi G-W, Kang H-W, Moon S-K: Repeated-batch fermentation using flocculent hybrid, Saccharomyces cerevisiae CHFY0321 for efficient production of bioethanol. Appl Microbiol Biotechnol 2009, 84(2):261-269.

47. Duarte J, Lourenço V, Ribeiro B, Saagua M, Pereira J, Baeta-Hall L: Ethanol Production from Different Substrates by a Flocculent Saccharomyces cerevisiae Strain. Int J Chem Reactor Eng 2009, 7(1):ISSN (Online) 1542-6580.

48. Li Q, Zhao X-Q, Chang AK, Zhang Q-M, Bai F-W: Ethanol-induced yeast flocculation directed by the promoter of TPS1encoding trehalose-6phosphate synthase 1 for efficient ethanol production. Metab Eng 2012, 14(1):1-8.

49. Leber R, Fuchsbichler S, Klobučníková V, Schweighofer N, Pitters E, Wohlfarter K, Lederer M, Landl K, Ruckenstuhl C, Hapala I, Turnowsky F: Molecular mechanism of terbinafine resistance in Saccharomyces cerevisiae. Antimicrob Agents Chemother 2003, 47(12):3890-3900.

50. Koller A, Valesco J, Subramani S: The CUP I promoter of Saccharomyces cerevisiae is inducible by copper in Pichia pastoris. Yeast 2000, 16:651-656.

51. Tronchoni J, Rozes N, Querol A, Manuel Guillamon J: Lipid composition of wine strains of Saccharomyces kudriavzevii and Saccharomyces cerevisiae grown at low temperature. Int J Food Microbiol 2012, 155(3):191-198.

52. Yan GL, Liang HY, Duan CQ, Han BZ: Enhanced production of betaCarotene by recombinant industrial wine yeast using grape juice as substrate. Curr Microbiol 2012, 64(2):152-158.

\section{Submit your next manuscript to BioMed Central and take full advantage of:}

- Convenient online submission

- Thorough peer review

- No space constraints or color figure charges

- Immediate publication on acceptance

- Inclusion in PubMed, CAS, Scopus and Google Scholar

- Research which is freely available for redistribution

Submit your manuscript at www.biomedcentral.com/submit
Ciomed Central 